\title{
Static Testing of the Buffering Capacity of Geological Material from an Abandoned Mine in Mpumalanga, South Africa
}

\author{
Elvis Fosso-Kankeu, Celetia Sahadave, Naythan van Wyk, Dumisane Moyakhe, Frans Waander, Marco \\ Le Roux and Quentin Campbell
}

\begin{abstract}
The mining industry generates large quantities of wastes that are disposed in tailing storage facilities (TSF). The acid mine drainage (AMD) from the gold mining industry contains a large number of toxic constituents and heavy metals which have serious consequences on the environment and on human health, if seeped into water sources. One of the solutions that have been considered to prevent AMD formation consists of cover systems for tailing storage facility. Cover systems containing alkaline geological material can be used to mitigate AMD formation as the alkaline geological material serves as buffering material. A well-implemented cover system with geological buffering material would keep the $\mathrm{pH}$ of the tailings constant which helps minimize potential environmental problems that can be experienced with low $\mathrm{pH}$ AMD. Static and kinetic tests (i.e. paste $\mathrm{pH}$ test, acid neutralization capacity (ANC) test, net acid generation (NAG) tests and acid buffering characteristic curve (ABCC) test) can be done to determine the acid generating and acid neutralizing capacity of the geological waste prior to consideration as cover system.
\end{abstract}

Keywords - acid mine drainage, acid mine drainage, gold, mitigation, net acid generation, acid neutralization capacity, acid buffering characteristic curve, geological material, buffering

\section{INTRODUCTION}

Acid mine drainage (AMD) has become a global crisis which progressively degrades our water sources. The United Nations (UN) announced that AMD is the second major environmental problem after global warming with it being a chronic problem in South Africa after years of mining. AMD is produced when the

E. Fosso-Kankeu is with the Water Pollution Monitoring and Remediation Initiatives Research Group, School of Chemical and Minerals Engineering, North-West University, Potchefstroom, South Africa

The Water Pollution Monitoring and Remediation Initiatives Research Group, School of Chemical and Minerals Engineering, North-West University, Potchefstroom, South Africa.

D. Moyakhe is with the Water Pollution Monitoring and Remediation Initiatives Research Group, School of Chemical and Minerals Engineering, North-West University, Potchefstroom, South Africa.

F.B. Waanders is with the Water Pollution Monitoring and Remediation Initiatives Research Group, School of Chemical and Minerals Engineering, North-West University, Potchefstroom, South Africa.

Q.P. Campbell is with the Coal Beneficiation Research Group in the School of Chemical and Minerals Engineering of the North West University, Potchefstroom-South Africa.

M. Le Roux is with the Coal Beneficiation Research Group in the School of Chemical and Minerals Engineering of the North West University, Potchefstroom-South Africa. tailings are exposed to oxygen and water [1-3]. The effluent formed is acidic and can affect the environment because of the low $\mathrm{pH}$ values, high sulphates and high concentrations of hazardous metals released from the AMD [4]. Contamination takes place when AMD reaches water sources such as surface or ground water used for industrial or human consumption [5]. Metal contamination of the surrounding water sources occurs from the sulphide oxidation processes. The water sources affected by pyrite oxidation are highly acidic and can accumulate in surface/ground water [5]. With respect to mine waste management and disposal of mine waste, AMD is one of the main environmental problems faced. The highly acidic polluted water has high concentrations of sulphates, iron and toxic metals which cause major health consequences of aquatic life and pollute the water used for human activities [6].

Pyrite $\left(\mathrm{FeS}_{2}\right)$ is a sulphur bearing mineral and one of the most common sulphide mineral found in AMD [7-9]. AMD is formed via a chemical reaction between water, oxygen and the sulphur bearing ore which leads to the formation of sulphuric acid and dissolved iron. $\mathrm{H}^{+}$atoms are produced thereof which lead to the low $\mathrm{pH}$ values [10]. The sulphide minerals are the primary redox components that react in the AMD. $\mathrm{H}^{+}$atoms are produced from this dissolution instead of being consumed like in many geochemical weathering processes. Pyrite is quickly dissolved in the presence of oxidants $\left(\mathrm{O}_{2}\right)$ and ferric ions $\left(\mathrm{Fe}^{3+}\right)$ but is relatively stable in alkaline and acidic conditions. The following chemical reactions from Park et al. illustrates this process [4],

$$
2 \mathrm{FeS}_{2}(\mathrm{~s})+7 \mathrm{O}_{2}+2 \mathrm{H}_{2} \mathrm{O}=2 \mathrm{Fe}^{2+}+4 \mathrm{SO}_{4}{ }^{2-}+4 \mathrm{H}^{+}
$$

In (1), the pyrite is oxidized by oxygen $\left(\mathrm{O}_{2}\right)$ and ferrous ions $\left(\mathrm{Fe}^{2+}\right)$, hydrogen ions $\left(\mathrm{H}^{+}\right)$and sulphate $\left(\mathrm{SO}_{4}^{2-}\right)$ is released.

$$
4 \mathrm{Fe}^{2+}+\mathrm{O}_{2}+4 \mathrm{H}^{+}=4 \mathrm{Fe}^{3+}+2 \mathrm{H}_{2} \mathrm{O}
$$

In the presence of an oxidizing environment, the ferrous ions are oxidized further into ferric ion $\left(\mathrm{Fe}^{3+}\right)$ in (2).

$$
\mathrm{Fe}^{3+}+3 \mathrm{H}_{2} \mathrm{O}=\mathrm{Fe}(\mathrm{OH})_{3}(\mathrm{~s})+3 \mathrm{H}^{2+}
$$

Thereafter, the ferric ion is precipitated or consumed to either form $\mathrm{Fe}(\mathrm{OH})_{3}$ (3) or reduced to form ferrous ions and more acid (4), respectively. This step depends on the $\mathrm{pH}$ of the 
environment. The oxidation of ferrous ion to ferric ion with oxygen is slow in acidic conditions. Therefore, pyrite oxidation via ferric ions should theoretically have a $\mathrm{pH}$ of less than 4.

$$
\mathrm{FeS}_{2}(\mathrm{~s})+14 \mathrm{Fe}^{3+}+8 \mathrm{H}_{2} \mathrm{O}=15 \mathrm{Fe}^{2+}+2 \mathrm{SO}_{4}{ }^{2-}+16 \mathrm{H}^{+}
$$

To combat the harmful environmental effects of AMD, AMD remediation techniques can be implemented. There are two types of remediation techniques, passive and active. Passive based techniques do not require continuous maintenance and have low operating costs whereas active based techniques need continuous manpower and chemical supply. Passive techniques are ineffective when the $\mathrm{pH}$ of the AMD is below 2, therefore the possibility of removing toxic heavy metals is very low. Active techniques need to be carried out for hundreds of years for the environmental benefits to be observed [4]. Unfortunately, this is unsustainable and not cost effective. Due to the limitations of the AMD remediation strategies mentioned above, mitigation of AMD formation is a more viable option to prevent harm to the environment. Acid mine drainage can be mitigated by studying the buffering potential of the geological material on the sulphur bearing minerals to prevent the formation of AMD. This can be deduced by determining the acid generating and neutralizing potential of the tailings as well as geological material.

Acid-base accounting (ABA) is a procedure that was developed in the 1960s which determines the acidic or alkaline production potential of the AMD. The ABA results fairly predicts the response of AMD upon weathering [11]. The following tests can be used to determine the acid-base account characteristics of the tailings, Paste $\mathrm{pH}$ test, Acid Neutralizing Capacity (ANC) test, Single Addition Net Acid Generation (NAG) test, Kinetic NAG test, Acid Buffering Characteristic Curve (ABCC) test.

The paste $\mathrm{pH}$ test is a test used to determine the acidity or alkalinity of the tailing sample. The paste $\mathrm{pH}$ test is a quick test as it provides immediate results about the acid nature of the sample. The test consists of mixing deionized water and the sample in a ratio of 2:1 and testing the $\mathrm{pH}$ at different time intervals. If the sample has a paste $\mathrm{pH}$ that is less than 4 , it can be concluded that the sample is potentially acid forming (PAF) [12]. Samples which have a paste $\mathrm{pH}$ of between 4 to 5 have a low acid content but are still considered potentially acid forming. A pH greater than 5 indicates that the sample has readily available acid generating capacity that is lesser than the acid neutralizing capacity. This results in a short lag time for AMD formation. For $\mathrm{pH}$ greater than 6 , a longer lag time to AMD formation is expected [13].

Acid neutralising capacity (ANC) is the buffering capacity of the tailing sample against acidification or to neutralise the sample. The ANC test was first created by Sobek et al. in 1978 and is done by digesting the crushed sample in hydrochloric acid at specific concentrations and volumes which are determined by the amount of readily available carbonates in the sample [14].

The ABCC is an indication of the portion of ANC within a sample that is readily available for acid neutralisation. The ABCC assesses whether the sample has enough readily available carbonates to render it non-acid forming if it has a NAPP $<0$ and a NAG pH of 4.5 [15].

The NAG tests are used in conjunction with the net acid production potential (NAPP) calculation to determine the acid forming potential of the tailing sample. The NAPP results can be critically analyzed using the single addition NAG test. This will provide a good indication as to whether the results obtained from the NAPP is accurate and reliable. The sample can fall into one of three categories namely potentially acid forming (PAF), non-acid forming (NAF) and uncertain (UC). The sample is considered PAF if the NAG pH is less than 4.5 and it has a positive NAPP. The sample is considered NAF if the NAG $\mathrm{pH}$ is greater than and equal to 4.5 and NAPP is negative. The sample is considered uncertain if there is a contradiction with the aforementioned domains [8]. The kinetic NAG test is a single addition NAG test but the $\mathrm{pH}$ and temperature are measured and monitored after the addition of hydrogen peroxide until the $\mathrm{pH}$ of the solution stabilizes [13]. The analysis of results is the same as with the single addition NAG test.

\section{Methodology}

\section{A. Sample collection and preparation}

Three samples were collected from an abandoned gold mine in Mpumalanga, South Africa. The samples collected from two different tailings storage facilities (TSFs) were acid generating and acid neutralizing samples, respectively. Two acid generating samples were collected from the top and bottom of one of the TSFs. These two samples are named Acid Generating Top (AGT) and Acid Generating Bottom (AGB). The second TSF contained the Acid Neutralizing (AN) sample which was the third sample. The samples were dried in the sun for 5 hours. Thereafter, the samples were sieved to obtain $<75 \mu \mathrm{m}$ particle size.

\section{B. Paste $\mathrm{pH}$ test}

The paste $\mathrm{pH}$ test is used to determine the acidic nature of TSF samples and provides an indication of immediate $\mathrm{pH}$ characteristics after mixing a crushed sample with water [13]. 5 grams of the $75 \mu \mathrm{m}$ sample was placed into $250 \mathrm{~mL}$ beakers. Pure water was added to the beaker in a ratio of 2:1 with a burette. The mixture was stirred with a glass rod for 10 seconds to form a paste. The $\mathrm{pH}$ was measured initially, then in time intervals of 10, 20 and 60 minutes. After each $\mathrm{pH}$ measurement, the solution was mixed for 10 seconds [12].

\section{Acid Neutralizing Capacity test}

To determine the reactive carbonates expected in the sample, a fizz rating is done. A few drops of $8 \% \mathrm{HCl}$ was added to $0.5 \mathrm{~g}$ of the $75 \mu \mathrm{m}$ sample and the intensity of the fizzing reaction that took place was observed. Based on the fizz rating, Table I can be used to determine the concentration of $\mathrm{HCl}$ and $\mathrm{NaOH}$ and the volume of $\mathrm{HCl}$ that is to be used in the ANC test [15]. 
TABLE I: FIZZ RATING

\begin{tabular}{lcccc}
\hline \hline Reaction & Fizz Rating & $\begin{array}{l}\mathrm{HCl} \\
\text { Molarity } \\
(\mathrm{M})\end{array}$ & $\begin{array}{l}\mathrm{HCl} \\
\text { Volume } \\
(\mathrm{M})\end{array}$ & $\begin{array}{l}\mathrm{NaOH} \\
\text { Molarity } \\
(\mathrm{M})\end{array}$ \\
\hline No reaction & 0 & 0.5 & 4 & 0.1 \\
Slight reaction & 1 & 0.5 & 8 & 0.1 \\
Moderate reaction & 2 & 0.5 & 20 & 0.5 \\
Strong reaction & 3 & 0.5 & 40 & 0.2 \\
Intense reaction & 4 & 1 & 40 & 0.5 \\
& 5 & 1 & 60 & 0.5 \\
\hline \hline
\end{tabular}

$2 \mathrm{~g}$ of the $75 \mu \mathrm{m}$ sample was digested for 1-2 hours between $80-90^{\circ} \mathrm{C}$ in $30 \% \mathrm{HCl}$ (volume and molarity determined by Table I) and $20 \mathrm{~mL}$ deionized water. The sample was allowed to cool and deionized water was added until a volume of $125 \mathrm{~mL}$ was obtained. The $\mathrm{pH}$ of this solution should be between $0.8-1.5$, if the $\mathrm{pH}$ is not within range then the aforementioned steps should be repeated. The digested solution was titrated with $\mathrm{NaOH}$ (molarity determined in Table I) to a pH of 5 with constant mixing. At a $\mathrm{pH}$ of $5,5 \mathrm{~mL}$ of $30 \% \mathrm{H}_{2} \mathrm{O}_{2}$ was added. The solution was titrated to a $\mathrm{pH}$ of 7 over 1-2 hours or until stable [12]. The solution was left overnight. The $\mathrm{pH}$ was measured and adjusted to 7 as required. 8 drops of $\mathrm{H}_{2} \mathrm{O}_{2}$ was added and left for 15 minutes. The $\mathrm{pH}$ was measured and adjusted to 7 as required. This was done until the solution was stable at a $\mathrm{pH}$ of 7 . The overnight step was repeated once more [14].

The equation to determine the ANC $\left(\mathrm{kg} \mathrm{H}_{2} \mathrm{SO}_{4} / \mathrm{t}\right)$ is shown below [9].

$A N C=\frac{\left(V_{H C l}-\left[V_{N a O H} \times \frac{V_{H C l, \text { Blank }}}{V_{\text {NaOH,Blank }}}\right]\right) \times M_{H C l}}{W} \times C$

$\mathrm{V}_{\mathrm{HCl}}=$ Volume of $\mathrm{HCl}$ added $(\mathrm{mL})$

$\mathrm{V}_{\mathrm{NaOH}}=$ Volume of $\mathrm{NaOH}$ added $(\mathrm{mL})$

$\mathrm{V}_{\mathrm{HCl}, \mathrm{Blank}}=$ Volume of $\mathrm{HCl}$ in blank $(\mathrm{mL})$

$\mathrm{V}_{\mathrm{NaOH}, \text { Blank }}=$ Volume of $\mathrm{NaOH}$ titrated in blank $(\mathrm{mL})$

$\mathrm{M}_{\mathrm{HCl}}=\mathrm{HCl}$ molarity (M)

$\mathrm{W}=$ Weight of sample (grams)

$\mathrm{C}=49\left(\right.$ for $\mathrm{kg} \mathrm{H}_{2} \mathrm{SO}_{4} / \mathrm{t}$ )

\section{Acid Buffering Characteristic Curve (ABCC)}

2 grams of sample was placed in a $250 \mathrm{~mL}$ conical flask and $100 \mathrm{~mL}$ of deionized water was added. The sample was titrated to $\mathrm{pH} 2.5$ with incremental additions of $\mathrm{HCl}$ (Table II) while stirring continuously. After each $\mathrm{HCl}$ addition, 1000 seconds were allowed for the $\mathrm{pH}$ to equilibrate. The $\mathrm{pH}$ was recorded and the $\mathrm{HCl}$ was converted to $\mathrm{kg} \mathrm{H}_{2} \mathrm{SO}_{4} / \mathrm{t}$. Then $\mathrm{kg} \mathrm{H}_{2} \mathrm{SO}_{4} / \mathrm{t}$ added (x-axis) against $\mathrm{pH}$ measured (y-axis) were plotted to obtain the buffering curve [15].

$$
\frac{\mathrm{kgH}_{2} \mathrm{SO}_{4}}{t} \text { added }=\frac{\mathrm{HCl} \text { added }(\mathrm{ml}) * \text { Molar Concentration } * 49}{W \text { of sample }(\mathrm{g})}
$$

TABLE II: SUGGESTED AMOUNTS OF HCL INCREMENTS

\begin{tabular}{ccc}
\hline \hline ANC of Sample $\left(\mathrm{kg} \mathrm{H}_{2} \mathrm{SO}_{4} / \mathrm{t}\right)$ & $\begin{array}{l}\mathrm{HCl} \text { Concentration } \\
(\mathrm{M})\end{array}$ & $\begin{array}{l}\mathrm{HCl} \text { increments } \\
(\mathrm{mL})\end{array}$ \\
\hline 10 & 0.1 & 0.1 \\
20 & 0.1 & 0.2 \\
50 & 0.1 & 0.5 \\
100 & 0.5 & 0.2 \\
200 & 0.5 & 0.4 \\
500 & 0.5 & 1 \\
1000 & 0.5 & 2 \\
\hline \hline
\end{tabular}

\section{E. Single Addition NAG test}

$250 \mathrm{~mL}$ of $15 \% \mathrm{H}_{2} \mathrm{O}_{2}$ was added (or $30 \% \mathrm{H}_{2} \mathrm{O}_{2}$ diluted $1: 1$ with deionized/distilled water) to $2.5 \mathrm{~g}$ of sample. The sample was reacted overnight in fume hood with a watch glass over the beaker. The sample was heated (with constant mixing) until gently bubbling for approx. 1-2 hours to remove excess $\mathrm{H}_{2} \mathrm{O}_{2}$ and to encourage the release of inherent neutralising capacity. Once cooled to room temperature, deionized water was added until the final volume was $250 \mathrm{~mL}$ and the $\mathrm{pH}$ of the NAG solution was measured. This is referred to as the NAG pH. The sample was titrated with $\mathrm{NaOH}$ to $\mathrm{pH} 4.5$ and then to $\mathrm{pH} 7$ (in $\mathrm{kg}$ $\mathrm{H}_{2} \mathrm{SO}_{4} / \mathrm{t}$ of sample). If the $\mathrm{NAG} \mathrm{pH}>2,0.1 \mathrm{M} \mathrm{NaOH}$ is used and if the $\mathrm{NAG} \mathrm{pH}=2,0.5 \mathrm{M} \mathrm{NaOH}$ is used [14].

$\operatorname{NAG}\left(\frac{\mathrm{kgH}_{2} \mathrm{SO}_{4}}{t}\right)=\frac{49 * V * M}{W}$

$\mathrm{V}$ - Volume of $\mathrm{NaOH}$ used in titration $(\mathrm{mL})$

$\mathrm{M}$ - Concentration of $\mathrm{NaOH}$ used in titration (mol/l)

$\mathrm{W}$ - Weight of sample (grams)

\section{F. Kinetic NAG test}

For the Kinetic NAG test, the $\mathrm{pH}$ and temperature were monitored during the single addition NAG test [14]. The initial starting temperature of the sample should be $20^{\circ} \mathrm{C}\left( \pm 2{ }^{\circ} \mathrm{C}\right)$. The $\mathrm{pH}$ and temperature were monitored during the $\mathrm{NAG}$ reaction using $\mathrm{pH}$ electrode and thermocouple. $250 \mathrm{~mL}$ of $15 \% \mathrm{H}_{2} \mathrm{O}_{2}$ (30\% $\mathrm{H}_{2} \mathrm{O}_{2}$ diluted 1:1 with deionized/distilled water) was added to $2.5 \mathrm{~g}$ of sample. The $\mathrm{pH}$ and temperature of the solution were measured and recorded immediately after addition of the $\mathrm{H}_{2} \mathrm{O}_{2}$. The $\mathrm{pH}$ and the temperature of the solution were measured until the $\mathrm{pH}$ stabilized or reached a $\mathrm{pH}$ below 4 [13].

\section{G. NAPP and Maximum Potential Acidity (MPA)}

To obtain the $\% \mathrm{~S}$, the samples were sent for Sulphur Speciation and were analysed with pyrolysis at $550{ }^{\circ} \mathrm{C}$. The maximum potential acidity (MPA) was calculated using (8) [15].

MPA $\left(\mathrm{kg} \mathrm{H}_{2} \mathrm{SO}_{4} / \mathrm{t}\right)=$ Total $\% \mathrm{~S} * 30.6$

The ANC and MPA can be used to calculate the Net Acid Producing Potential (NAPP). The NAPP (in $\mathrm{kg} \mathrm{H}_{2} \mathrm{SO}_{4}$ ) is calculated in (9), 
$\mathrm{NAPP}=\mathrm{ANC}-\mathrm{MPA}$

(9)

\section{RESULTS AND DISCUSSION}

TABLE III: SULPHUR SPECIATION

\begin{tabular}{llll}
\hline \hline & AGT & AGB & AN \\
\hline Total Sulphur (\%) ELTRA & 0.08 & 0.43 & 0.07 \\
Sulphide Sulphur (\%) & 0.07 & 0.35 & 0.06 \\
\hline \hline
\end{tabular}

The Total Sulphur (\%) is considered when doing the MPA calculation as the difference between the Total Sulphur and Sulphide Sulphur percentages is small. Using the Total Sulphur (\%) also ensures that the MPA is not underestimated.

The results of each static test is summarized in Table IV.

TABLE IV: RESULTS

\begin{tabular}{llll}
\hline \hline Channels & AGT & AGB & AN \\
\hline Paste $\mathrm{pH}$ & 3.23 & 2.29 & 7.46 \\
NAG $\mathrm{pH}$ & 3.43 & 3.05 & 6.13 \\
NAG at $\mathrm{pH}_{4.5}$ & 1.04 & 4.51 & 0 \\
NAG at $\mathrm{pH}_{7}$ & 9.73 & 13.91 & 3.59 \\
Kinetic NAG & 4.88 & 3.58 & 6.04 \\
ANC at $\mathrm{pH}_{7}$ & 0 & 0 & 5259.72 \\
MPA & 2.45 & 13.16 & 2.14 \\
NAPP & 2.45 & 13.16 & -5257.58 \\
\hline \hline
\end{tabular}

The ANC test resulted in negative ANC values which indicates that there is no acid neutralizing capacity in the AGT and AGB samples.

From the results obtained, the Neutralisation Potential Ratio (NPR) can be calculated (10) [16].

$N P R=\frac{A N C}{M P A}$

A NPR value of less than 1 indicates that the sample is potentially acid forming (PAF). A value greater than 2.5 is considered non-acid forming (NAF), and a value between 1 and 2.5 is uncertain [16]. The NPR obtained for the AGT and AGB samples were both 0 which is less than 1, indicating that the sample is PAF. The NPR obtained for the AN sample is greater than 2.5 which indicates that the sample is non-acid producing. This also corresponds with the NAG results, the NAPP of the AN sample is $<0$ and the NAG pH is $>4.5$, also indicating that the sample is NAF. The acid generating samples (AGT and AGB) have a NAPP $>0$ and NAG pH $<4.5$ which also confirms the PAF result obtained from the NPR.

The ABCC of the three samples can be seen below in Fig. 1, Fig.2 and Fig.3.

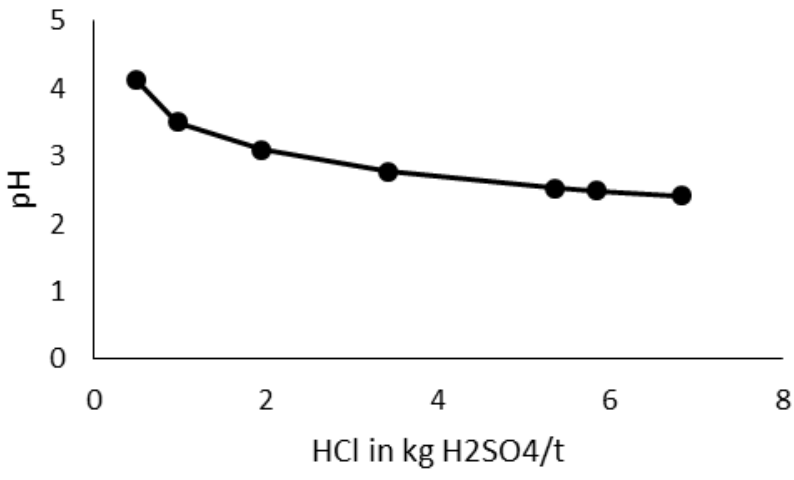

Fig. 1. ABCC of AGT sample.

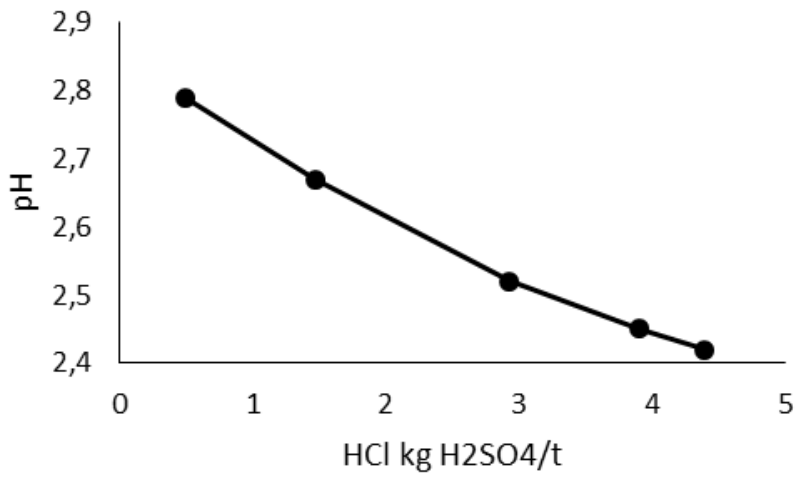

Fig. 2. ABCC of AGB sample.

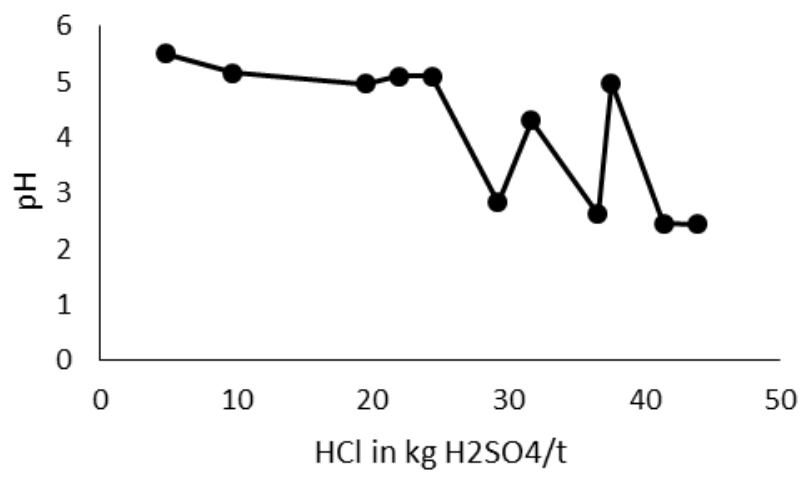

Fig. 3. ABCC of AN sample.

According to the $\mathrm{ABCC}$ of the acid generating samples (Fig.1 and Fig.2), a rapid drop in $\mathrm{pH}$ is observed when acid is added. This indicates a slow reactivity of the available carbonates in the samples or a lack of ANC in the samples. However, the AN sample has readily available carbonates for acid neutralization. This can be observed in Fig.3. as the readily available carbonates react with the acid added and the $\mathrm{pH}$ of the sample varies between 4.3 and 5.5 until it eventually drops to a $\mathrm{pH}$ of 2.5.

\section{CONCLUSION}

In conclusion, the acid generating samples have no acid neutralizing capacity and immediate action should be taken to mitigate more acid formation. The acid neutralizing sample has a high ANC value and can be used to buffer the acid generating 
samples to mitigate the formation of AMD for a time to be determined. The opportunity to use waste for the mitigation of AMD formation will ensure the sustainability of the remediation process.

\section{ACKNOWLEDGMENT}

Author EFK acknowledged the financial support from the National Research Foundation (NRF) in South Africa (Grant No: 120323); Any opinion, findings and conclusions or recommendations expressed in this material are those of the authors and therefore the NRF does not accept any liability in regard thereto.

\section{REFERENCES}

[1] Fosso-Kankeu E, Mulaba-Bafubiandi A, Mamba BB, Barnard TG. 2011. Assessing the effectiveness of a biological recovery of nickel from tailings dumps. Journal of Minerals Engineering.Vol 24, pp 470-472 https://doi.org/10.1016/j.mineng.2010.11.007

[2] Elvis Fosso-Kankeu, Alusani Manyatshe, Frans Waanders. 2017. Mobility potential of metals in acid mine drainage occurring in the Highveld area of Mpumalanga Province in South Africa: Implication of sediments and efflorescent crusts. International Biodeterioration and Biodegradation. 119: 661-670. https://doi.org/10.1016/j.ibiod.2016.09.018

[3] E Fosso-Kankeu. 2018. Synthesized af-PFCl and GG-g-P(AN)/TEOS hydrogel composite used in hybridized technique applied for AMD treatment. Journal of Physics and Chemistry of the Earth. 105: 170-176. https://doi.org/10.1016/j.pce.2018.02.015

[4] Park, I., Tabelin, C. B., Jeon, S., Li, X., Seno, K., Ito, M., \& Hiroyoshi, N. (2019). A review of recent strategies for acid mine drainage prevention and mine tailings recycling. Chemosphere, 219, 588-606. https://doi.org/10.1016/j.chemosphere.2018.11.053

[5] Pozo-Antonio, S., Puente-Luna, I., Lagüela-López, S., \& Veiga-Ríos, M. (2014). Techniques to correct and prevent acid mine drainage: A review. Dyna, 81(186), 73. https://doi.org/10.15446/dyna.v81n186.38436

[6] Ríos, C. A., Williams, C. D., \& Roberts, C. L. (2008). Removal of heavy metals from acid mine drainage (AMD) using coal fly ash, natural clinker and synthetic zeolites. Journal of Hazardous Materials, 156(1-3), 23-35. https://doi.org/10.1016/j.jhazmat.2007.11.123.

[7] Fosso-Kankeu Elvis and Redelinghuys Johannes. 2018. Bacterial ecology of biofilms sustaining pollution by acid mine drainage near mining areas in Mpumalanga Province - South Africa. $11^{\text {th }}$ ICARD/IMWA/MWD Conference "Risk to Opportunity". 10-14 September 2018 Pretoria, South Africa. C. Wolkersdorfer, L. Sartz, A. Weber, J. Burgess, G. Tremblay.ISBN: 978-0-620-80650-3 Vol 1 (2 volumes).

[8] Elvis Fosso-Kankeu, Christian Wolkersdorfer and Jo Burgess. 2020. Recovery of byproducts from acid mine drainage treatment. Wiley Scrivener. ISBN: 978-1-119-62018-1.

https://doi.org/10.1002/9781119620204

[9] Innocentia G. Erdogan, Elvis Fosso-Kankeu, Seteno K.O. Ntwampe, Frans B. Waanders, Nils Hoth. 2020. Management of Metalliferous Solid Mine Waste and its Potential to Contaminate Groundwater: A Case Study of O'Kiep, Namaqualand South Africa. In Recovery of byproducts from acid mine drainage treatment. Editors: Elvis Fosso-Kankeu, Christian Wolkersdorfer and Jo Burgess. Wiley Scrivener. ISBN: 978-1-119-62018-1.

https://doi.org/10.1002/9781119620204.ch1

[10] Akcil, A., \& Koldas, S. (2006). Acid Mine Drainage (AMD): causes, treatment and case studies. Journal of Cleaner Production, 14(12-13 SPEC. ISS.), 1139-1145. https://doi.org/10.1016/j.jclepro.2004.09.006

[11] Skousen, J. (2017). A methodology for geologic testing for land disturbance: Acid-Base Accounting for surface mines. Geoderma, 308(October 2016), 302-311. https://doi.org/10.1016/j.geoderma.2017.07.038

[12] Yucel, D. S., \& Baba, A. (2016). Prediction of acid mine drainage generation potential of various lithologies using static tests : Etili coal mine (NW Turkey) as a case study. Environmental Monitoring and Assessment. https://doi.org/10.1007/s10661-016-5462-5

[13] Weber, P. A., Waste, M., \& Lindsay, P. (2006). Short-term acid rock drainage characteristics determined by paste ph and kinetic nag testing: cypress prospect, new zealand1 short-term acid rock drainage characteristics determined by paste ph and kinetic nag testing: CYPRESS. May 2016. https://doi.org/10.21000/JASMR06022289

[14] Stewart, W. A., Miller, S. D., \& Smart, R. (2006). ADVANCES IN ACID ROCK DRAINAGE (ARD) CHARACTERISATION OF MINE WASTES 1. 2098-2119. https://doi.org/10.21000/JASMR06022098

[15] Yucel, D. S., \& Baba, A. (2016). Prediction of acid mine drainage generation potential of various lithologies using static tests: Etili coal mine (NW Turkey) as a case study. Environmental Monitoring and Assessment. https://doi.org/10.1007/s10661-016-5462-5

[16] Qureshi, A., Maurice, C., \& Öhlander, B. 2016. Potential of coal mine waste rock for generating acid mine drainage. Journal of Geochemical Exploration, 160, 44-54. https://doi.org/10.1016/j.gexplo.2015.10.014 